With respect to distribution, 122 patients $(95.3 \%)$ had al least one joint with US synovitis and 76 patients $(59.3 \%)$ had at least one joint with PD. The wrist, 2nd MCPj and 2nd metatarsophalangeal joint (MTPj) were the most affected in terms of synovitis whereas the 5th MTPj showed more erosions (37.7\%) and the extensor fingers tendons showed more tenosynovitis (23.02\%).

Conclusions: US demonstrated to play an important role in the treatment decision of RA patients. The impact was more frequent in patients with active disease but also affected the decision in patients considered in clinical remission. Disclosure of Interest: None declared

DOI: 10.1136/annrheumdis-2017-eular.6689

\section{FRI0661 CAPILLAROSCOPY IN PATIENTS WITH SILICA EXPOSURE. A CASE CONTROL STUDY}

M. Freire ${ }^{1}$, A. Perez-Gonzalez ${ }^{1}$, V. Arnalich ${ }^{2}$, D. Boveda-Ruiz ${ }^{1}$, A. Salgado ${ }^{3}$, J.J. Blanco-Perez ${ }^{2}{ }^{1}$ Unidad de Enfermedades Autoinmunes Sistémicas y Trombosis; ${ }^{2}$ Servicio de Neumología, Complejo Hospitalario Universitario de Vigo; ${ }^{3}$ Unidad de apoyo a la investigación, Instituto de Investigación Biomedica de Ourense-Pontevedra-Vigo, Vigo, Spain

Background: Exposure to silica dust has been associated with different autoimmune diseases and immunological abnormalities in which microvascular involvement is very common, as systemic sclerosis, systemic lupus erythematosus, rheumatoid arthritis or dermatomyositis.

Objectives: To show capillaroscopic findings in patients exposed and not exposed to silica and to analyze the differences between both groups.

Methods: A case control design was made. Cases ( $\mathrm{Si}+$ ) were subjects exposed to silica (with and without silicosis). Controls (Si-) were healthy subjects not exposed to silica. Capillaroscopy was made with both Zuzi ${ }^{\circledR}$ Optical stereo microscope with Optikam ${ }^{\circledR}$ camera adapted and with USB Digital Microscope Video epiluminiscence Dino-Lite ${ }^{\circledR}$ in each patient. The capillaroscopic alterations were evaluated according to a semiquantitative method. Background data on CVRF and variables related to capillaroscopy were collected. A comparative study was done. Results: Capillaroscopy was performed on $61 \mathrm{Si}+$ and $12 \mathrm{Si}$ - subjects. Mean age of $\mathrm{Si}+$ was 52.6 years (SD: 7.3 ) and 54 years (SD: 6.6) in Si-. There were no significant differences in CVRF: hypertension (13.1\% $\mathrm{Si}+$ and $8.3 \% \mathrm{Si}-)$, diabetes mellitus (3.3\% Si+ and $8.3 \% \mathrm{Si}-)$ and tobacco exposure $(18.0 \% \mathrm{Si}+$ and $25.0 \%$ $\mathrm{Si}-$ ). It was observed capillary dilation in $24(33.9 \%) \mathrm{Si}$ and only in $3(25.0 \%) \mathrm{Si}-$. The dilation score was mild in all $\mathrm{Si}$ - while in $\mathrm{Si}+$ was mild in $41.7 \%$, moderate in $37.5 \%$ and extreme in $12.5 \% .42 .7 \%$ of $\mathrm{Si}+$ had a degree of tortuosity higher than $33 \%$ (score 2) whereas in all Si- the degree of tortuosity was $<33 \%$ (score 1). Capillaroscopic general pattern showed differences between both groups: it was normal in $24(42.1 \%) \mathrm{Si}+$ and 9 (75\%) Si-; slightly irregular in $30(52.6 \%) \mathrm{Si}+$ and $3(25 \%)$ Si- and unstructured in $3 \mathrm{Si}+(5.3 \%)$ and in none $\mathrm{Si}-$

Conclusions: The current study shows significant differences between the capillaroscopy of subjects exposed and not exposed to silica, with a trend in more frequency and severity of capillary dilatation, greater frequency of tortuosity in a severe degree and more frequent irregular capillaroscopic pattern in the exposed patients.

References:

[1] Blanc PD, Järvholm B, Torén K. Prospective risk of rheumatologic disease associated with occupational exposure in a cohort of male construction workers. Am J Med 2015;128(10):1094-101.

Disclosure of Interest: None declared

DOI: 10.1136/annrheumdis-2017-eular.4132

\section{FRI0662 ASSESSMENT OF BONE DENSITY, STRUCTURE, AND CORTICAL INTERRUPTIONS OF FINGER JOINTS IN PATIENTS WITH RHEUMATOID ARTHRITIS USING HIGH-RESOLUTION} PERIPHERAL QUANTITATIVE CT

M. Peters ${ }^{1}$, A. Scharmga ${ }^{1}$, A. van Tubergen ${ }^{1}$, D. Loeffen ${ }^{1}$, R. Weijers ${ }^{1}$, B. van Rietbergen ${ }^{1,2}$, P. Geusens ${ }^{1}$, J. van den Bergh ${ }^{1} .{ }^{1}$ MUMC, Maastricht; ${ }^{2}$ TU/e, Eindhoven, Netherlands

Background: Rheumatoid arthritis (RA) is characterized by peri-articular bone loss. In patients with RA, lower bone density and structural integrity, and an increased number of erosions compared to healthy controls ( $\mathrm{HCs}$ ) has been demonstrated using High-Resolution peripheral Quantitative CT (HR-pQCT) $(1,2)$. To further characterize RA-related changes, we recently introduced a method for quantifying small cortical interruptions in finger joints (3).

Objectives: To investigate the cortical and trabecular bone density, structure, and cortical interruptions in MCP joints in early and late RA patients compared to HCs using HR-pQCT imaging.

Methods: The 2nd and 3rd MCP joint of 70 subjects (mean age 53.1 (SD 9.2) years) were evaluated by HR-pQCT ( $82 \mu \mathrm{m}$ isotropic voxel size): $38 \mathrm{HCs}, 10$ early RA (diagnosis $\leq 2$ years ago) and 22 late $R A$ (diagnosis $\geq 10$ years ago). Images were analyzed for cortical interruptions, and for cortical and trabecular bone density and structure. Descriptives were analyzed per joint by one-way ANOVA with Bonferroni post-hoc testing or Kruskal-Wallis with Mann-Whitney post-hoc testing, as appropriate.

Results: Significant differences with respect to all parameters were found across the groups (Table 1). In early and late RA, the percentage of joints with at least
1 interruption was higher, and number of trabeculae, cortical thickness, total density and cortical density were lower than in HC. In addition, in late RA, number of interruptions, interruption volume and trabecular separation were higher, and trabecular density was lower than in $\mathrm{HC}$. Bone loss at the cortical and trabecular bone was primarily observed at the rim of the joint (Figure 1, arrows).

Table 1. Comparison of cortical interruptions, and bone density and structure parameters across early RA patients, late RA patients and $\mathrm{HCs}$

\begin{tabular}{|c|c|c|c|c|}
\hline & $\mathrm{HC}$ & Early RA & Late RA & $\mathrm{p}$-value \\
\hline Cortical interruption parameters & $\mathrm{n}=82$ & $n=39$ & $\mathrm{n}=73$ & \\
\hline Percentage of joints $\geq 1$ interruption, $\%$ & 69.5 & $89.7^{*}$ & 82.2 & 0.025 \\
\hline Number of interruptions & $1.50(1.49)$ & $2.64(2.95)$ & $5.22^{\star}(6.32)$ & $<0.001$ \\
\hline Interruption volume, $\mathrm{mm}^{3}$ & $1.49(5.16)$ & $2.05(6.76)$ & $39.31^{*}(78.51)$ & $<0.001$ \\
\hline Bone density parameters & $\mathrm{n}=50$ & $\mathrm{n}=31$ & $\mathrm{n}=68$ & \\
\hline Total vBMD, $\mathrm{mg} \mathrm{HA} / \mathrm{cm}^{3}$ & $327.3(35.3)$ & $295.8^{\star}(38.9)$ & $286.4^{\star}(65.1)$ & $<0.001$ \\
\hline Trabecular vBMD, $\mathrm{mg} \mathrm{HA} / \mathrm{cm}^{3}$ & $202.1(20.6)$ & $185.0(21.6)$ & $177.3^{\star}(42.0)$ & $<0.001$ \\
\hline Cortical vBMD, $\mathrm{mg} \mathrm{HA} / \mathrm{cm}^{3}$ & $685.8(42.8)$ & $643.7^{*}(58.2)$ & $634.0^{*}(73.3)$ & $<0.001$ \\
\hline Bone structure parameters & $n=50$ & $n=31$ & $\mathrm{n}=68$ & \\
\hline Trabecular number, $\mathrm{mm}^{1}$ & $1.68(0.31)$ & $1.45^{\star}(0.29)$ & $1.52^{\star}(0.37)$ & 0.004 \\
\hline Trabecular thickness, $\mu \mathrm{m}$ & $102.3(15.3)$ & $109.1(17.8)$ & $98.6(14.7)$ & 0.009 \\
\hline Trabecular separation, $\mu \mathrm{m}$ & $513.9(116.9)$ & $608.4(132.3)$ & $611.4^{\star}(220.6)$ & 0.007 \\
\hline \multicolumn{5}{|l|}{ Distribution of trabecular } \\
\hline sepa & $550.6(287.0)$ & $728.5(306.1)$ & $689.4(368.8)$ & 0.029 \\
\hline Cortical thickness, $\mu \mathrm{m}$ & $440.0(99.2)$ & $363.2^{\star}(90.2)$ & $357.5^{\star}(132.8)$ & $<0.001$ \\
\hline
\end{tabular}

Values are displayed as mean (SD) or otherwise described. *Significantly different from HC, $p<0.05$. ${ }^{1} p$-value obtained across the groups. vBMD, volumetric bone mineral density.

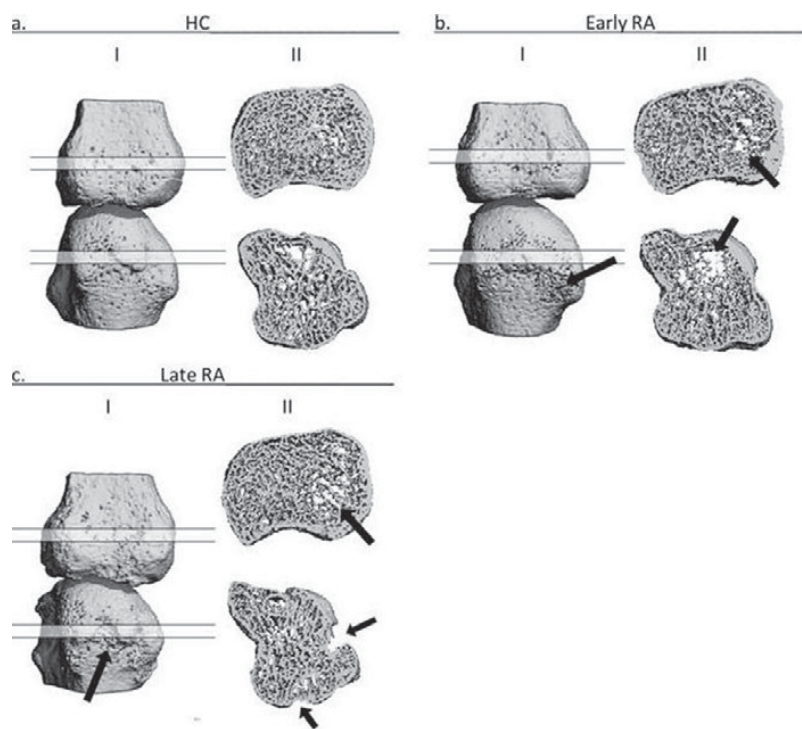

Figure 1. Typical examples of MCP joints; (a) HC, (b) early RA patient, and (c) late RA patient. The total $3 D$ reconstructions are shown (I.) with corresponding 20slices thick axial slices (II). The arrows indicate locations of loss of trabecular and/or cortical structure in the early and late RA patients compared to the HC.

Conclusions: Bone density and structural integrity were impaired in early and late RA patients compared to HCs whereas the number of cortical interruptions is increased. The assessment of such parameters using HR-pQCT is, therefore, a promising tool for the follow-up of bone involvement in MCP joints in patients with RA

\section{References:}

[1] Fouque-Aubert et al., ARD 2010.

[2] Stach et al., A\&R 2010.

[3] Peters et al., ACR2016 (abstract).

Disclosure of Interest: M. Peters: None declared, A. Scharmga: None declared, A. van Tubergen: None declared, D. Loeffen: None declared, R. Weijers: None declared, B. van Rietbergen Consultant for: Scanco Medical AG, P. Geusens: None declared, J. van den Bergh: None declared

DOI: 10.1136/annrheumdis-2017-eular.4743

\section{FRI0663 EVALUATION OF A FLUOROENZYME IMMUNOASSAY (ELIA-CTD) IN THE SCREENING OF PATIENTS SUSPECTED FOR AUTOIMMUNE CONNECTIVE TISSUE DISEASES}

M. Elkhalifa ${ }^{1}$, R. Abdulhadi ${ }^{1}, \mathrm{H}$. Ramadan ${ }^{1}$, S. Barrientos ${ }^{1}$, S. Saleh ${ }^{1}$, O. Suhial ${ }^{2}$, A.W. Al-Allaf ${ }^{2} .{ }^{1}$ Laboratory Medicine \& Pathology; ${ }^{2}$ Medicine, Hamad Medical Corporation, Doha, Qatar

Background: Detection of auto-antibodies directed against nuclear antigens (antinuclear antibodies or ANA) have important diagnostic and prognostic implications in connective tissue diseases (CTD). The conventional indirect immunofluorescence assay on HEp-2 cell line (ANA-IIF) is the most commonly used method to detect ANA. The ANA-IIF can be labor intensive and suffers from lack of specificity. 